\title{
Cutaneous Melanoma pM1c TNM Finding
}

National Cancer Institute

\section{Source}

National Cancer Institute. Cutaneous Melanoma pM1c TNM Finding. NCI Thesaurus.

Code C48869.

Cutaneous melanoma with metastases to all other visceral sites associated with normal serum lactate dehydrogenase (LDH) or distant metastases to any site associated with an elevated serum LDH. (from AJCC 6th and 7th Eds.) 